CORRIGENDUM

doi:10.1038/nature11168

\title{
Corrigendum: Fetal load and the evolution of lumbar lordosis in bipedal hominins
}

Katherine K. Whitcome, Liza J. Shapiro \& Daniel E. Lieberman

Nature 450, 1075-1078 (2007); doi:10.1038/nature06342

In this Letter, Fig. $4 a$ appeared incorrectly (see corrected figure below). The correct equation used to calculate vertebral wedging is: $2 \arctan \{[$ (centrum dorsal height minus centrum ventral height)/2]/ centrum anteroposterior diameter\}, but the correction constant of 2 was inadvertently omitted. As a result, the australopithecine wedging angles reported are half the correct values. However, after correction, our original inference of similarity in sex-related patterns of vertebral wedging among bipedal hominins remains strongly supported. We thank K. Ostrofsky, S. A. Williams and S. Churchill for drawing this error to our attention. Figure $4 \mathrm{a}$ has been corrected in the HTML and $\mathrm{PDF}$ versions online.

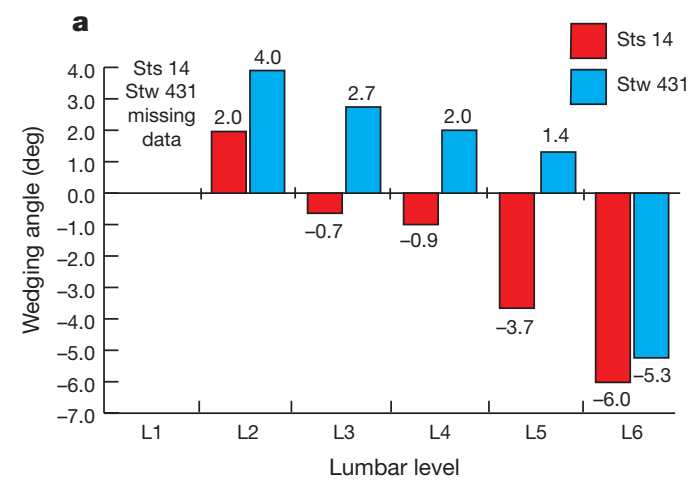

Figure $1 \mid$ This is the corrected Fig. 4a of the original Letter. 